\title{
Electromagnetic energy harvester for harvesting acoustic energy
}

\author{
FARID U KHAN* and IZHAR \\ Institute of Mechatronics Engineering, University of Engineering and Technology, Peshawar 25000, Pakistan \\ e-mail: dr_farid_khan@uetpeshawar.edu.pk
}

MS received 18 May 2015; revised 3 August 2015; accepted 16 October 2015

\begin{abstract}
This paper reports a suspended coil, electromagnetic acoustic energy harvester (AEH) for extracting acoustical energy. The developed AEH comprises Helmholtz resonator (HR), a wound coil bonded to a flexible membrane and a permanent magnet placed in a magnet holder. The harvester's performance is analyzed under different sound pressure levels (SPLs) both in laboratory and in real environment. In laboratory, when connected to $50 \Omega$ load resistance and subjected to an SPL of $100 \mathrm{~dB}$, the AEH generated a peak load voltage of $198.7 \mathrm{mV}$ at the resonant frequency of $319 \mathrm{~Hz}$. When working under the optimum load resistance, the AEH generated an optimum load power of $789.65 \mu \mathrm{W}$. In real environment, the developed AEH produced a maximum voltage of $25 \mathrm{mV}$ when exposed to the acoustic noise of a motorcycle and generated an optimum voltage of $60 \mathrm{mV}$ when it is placed in the surroundings of a domestic electrical generator.
\end{abstract}

Keywords. Acoustics; energy harvesting; electromagnetic; Helmholtz resonator; sound pressure level; suspended coil.

\section{Introduction}

In the last few years, with the rapid developments in microscale sensors, microelectronics, ultra large scale of integration (ULSI) and wireless communication networks, wireless sensor nodes (WSNs) appeared as one of the broadly used systems to sense and monitor, Khan and Izhar [1]. WSNs mostly consist of a sensor, microcontroller, signal conditioning circuit, power management circuit and RF transmitter. Batteries are used to provide energy to WSNs, which are supposed to operate for longer period of time. However the life span of batteries is limited, that is a real bottleneck for the applications of WSNs in remote, hazardous and embedded environment [2-4]. Alternatively, energy harvesting from the environment of wireless sensors can be utilized to enhance the life of batteries and operate WSN for greater time duration. In the surrounding of WSNs several ambient energies such as wind, thermal, vibration, and solar are available and have been successfully transformed into the useful energy with the aid of energy harvesters developed by Tan and Panda [5], Kang et al [6], Elfrink et al [7], Khan et al [8], Khan et al [9] and Georgiadis et al [10] respectively. Moreover, acoustical noise is also present in abundance in the surroundings [11-15]. Converting ambient acoustical noise with an acoustic energy (AEH) into a useful electrical power is most appropriate for applications like health monitoring of vehicles, machineries, buildings and bridges.

*For correspondence
Several AEHs based on electromagnetic and piezoelectric conversion methods are reported. The internal impedance of electromagnetic based energy harvesters is relatively smaller than that of piezoelectric based energy harvesters, due to which these energy harvesters have the advantage of generating relatively high power levels [16].

For aero-acoustic applications a MEMS-scale piezoelectric AEH is reported by Horowitz et al [17]. The developed AEH comprises HR and a Lead Zirconate Titanate (PZT) membrane. The harvester generated a maximum power of $6 \mathrm{pW}$ at a resonant frequency of $13.57 \mathrm{kHz}$. Peng et al [18] developed a wideband piezoelectric AEH which consisted of a holed plate (brass), two HRs and a rectangular PZT membrane attached to the plate. A peak power of $7.5 \mu \mathrm{W}$ at a frequency of $1358 \mathrm{~Hz}$ is reported for the developed harvester. A novel piezoelectric type AEH composed of a circular piezoelectric plate is developed by Kimura et al [19]. To increase the efficiency of the AEH, a non-wet etching process is used to develop the piezoelectric plate. At $16.7 \mathrm{kHz}$ resonant frequency, the energy harvester generated a peak power of $140 \mathrm{pW}$. An improved piezoelectric AEH reported by lizumi et al [20] is composed of a piezoelectric membrane having one bottom and two dual top electrodes. The resonant frequency of the developed harvester is $4.92 \mathrm{kHz}$. The reported peak power for the energy harvester under resonance condition is $82.8 \mathrm{pW}$. Li et al [21] developed an improved piezoelectric AEH for low frequency acoustic environment. In the harvester, piezoelectric plates are fixed in a long quarterwavelength straight channel. The AEH at $146 \mathrm{~Hz}$ resonant 
frequency harvested a peak power of $2.2 \mu \mathrm{W}$. A wide band piezoelectric AEH developed by Yang et al [22] is comprised of a couple of piezoelectric beams and a HR. On top of the HR, piezoelectric beams are fixed to form the energy harvester. Optimum power obtained from the harvester at $201 \mathrm{~Hz}$ resonant frequency is $1.43 \mathrm{~mW}$.

For portable electronic devices Lai et al [23] reported an electromagnetic AEH. To develop the harvester, a nickel planar spring, a neodymium $(\mathrm{NdFeB})$ magnet and a nickel planar coil are utilized. For the harvester a $0.24 \mathrm{mV}$ open circuit voltage is reported. Khan and Izhar [16] reported an electromagnetic AEH for WSN applications. The harvester comprises a suspension system that composed of a couple of $\mathrm{NdFeB}$ magnets mounted on a latex membrane, a $\mathrm{HR}$, and a static wound coil. Moreover, a peak power of $1.5 \mathrm{~mW}$ at $146 \mathrm{~Hz}$ resonant frequency is reported for the harvester.

In the entire electromagnetic AEH reported in the literature the coil is fixed; however, the magnet is movable and attached to the membrane of the harvester. However, the moving magnet architecture is more prone to catastrophic destruction in case the harvester accidently comes near or in contact to the ferromagnetic part in the surroundings. If this happened the membrane part of the harvester would be completely destroyed. In the alternate harvester's architecture the coil can be made movable and the magnet is kept stationary. Even in this architecture the fixed magnet of the device can be exploited to attach the harvester to the ferromagnetic components and parts located in the surrounding of the acoustical noise. To eliminate the short comings of the oscillating magnet type electromagnetic energy harvesters, an improved electromagnetic AEH with a static permanent magnet and oscillating coil is developed in this work. The developed energy harvester comprises a HR, a suspension system composed of a wound coil bounded on a latex membrane and a permanent magnet positioned in a magnet holder just beneath the coil. Relatively larger magnet is used due to which relatively high voltage and power levels are expected.

\section{Operational mechanism and architecture of the prototype}

In figure 1 the architecture of the developed $\mathrm{AEH}$ is depicted.

The AEH developed in this work comprises a Helmholtz resonator, a suspension system composed of a wound coil mounted on a thin membrane, an $\mathrm{NdFeB}$ permanent magnet and a magnet holder. The membrane (coil) and the static magnet are held apart by some gap to allow the vibration of coil over the static magnet. Moreover, to minimize the losses due to air damping on the magnet side, air passages are provided in magnet holder portion of the harvester.

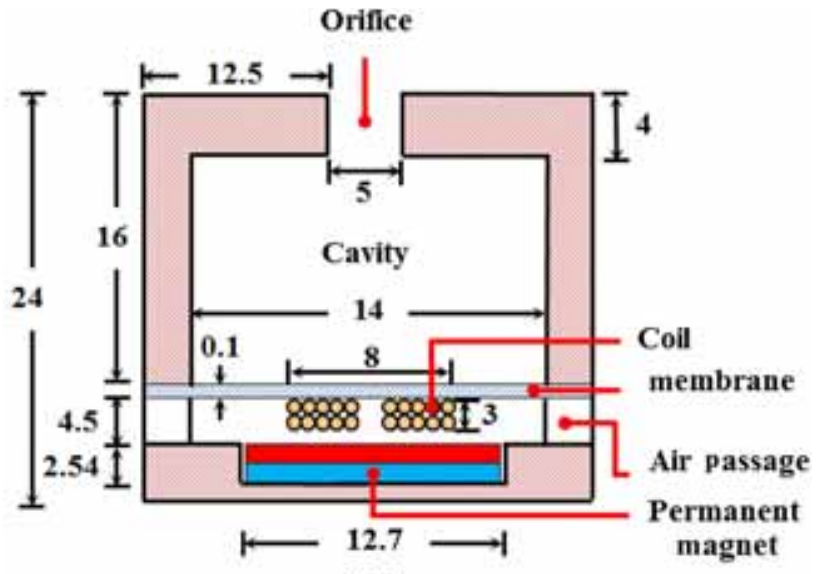

(a)

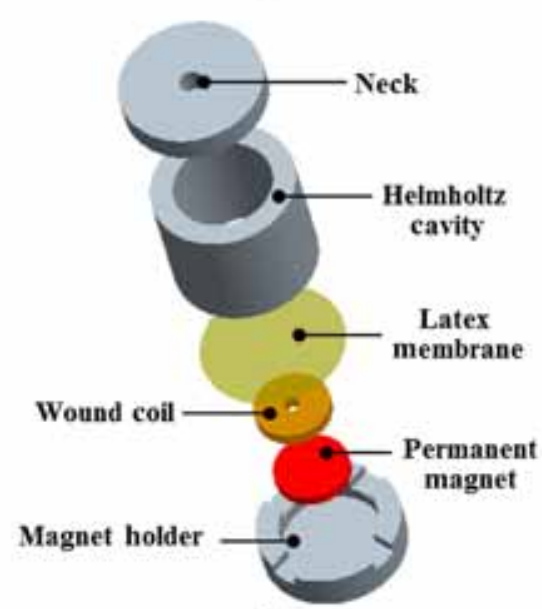

(b)

Figure 1. Developed AEH: (a) cross-section view (dimensions in $\mathrm{mm}$ ), (b) exploded view.

When an acoustic wave impinges on the harvester, the HR amplifies the wave [24, 25] which results in the motion of the membrane (coil) relative to the static $\mathrm{NdFeB}$ magnet. Because of this motion a variation in magnetic flux is experienced by coil and voltage is generated by the coil across its terminal. Due to the nature of the acoustic wave, the lumped mass of air residing at the neck oscillates which causes a fluctuating pressure inside the cavity of the HR. when the lumped mass enters into the cavity the inside pressure increases above ambient pressure. However, when the lumped mass moves out the cavity, the pressure drops from the ambient pressure. This fluctuating pressure causes the membrane of the harvester to vibrate.

\section{Prototype fabrication}

In figure 2 the assembly steps of the developed AEH prototype are depicted. Utilizing the commercially accessible $15.9 \mathrm{~mm}$ radius Teflon bar (WS Hampshire Inc. 


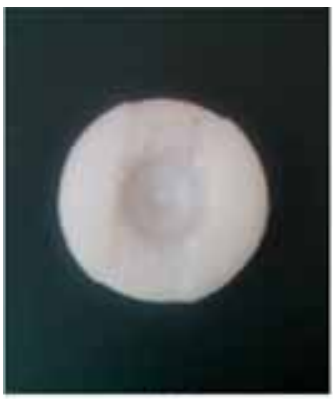

(a)

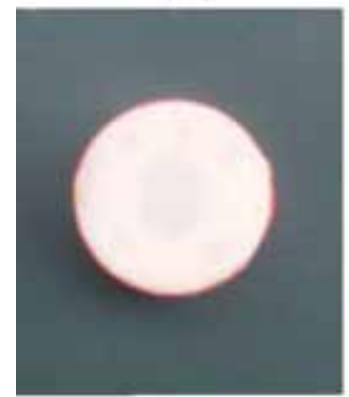

(c)

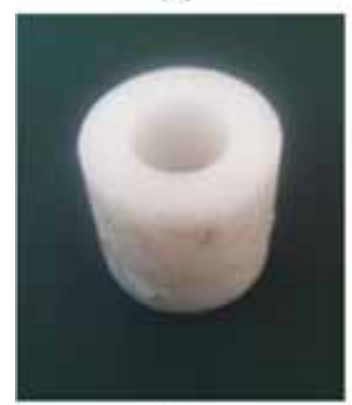

(e)

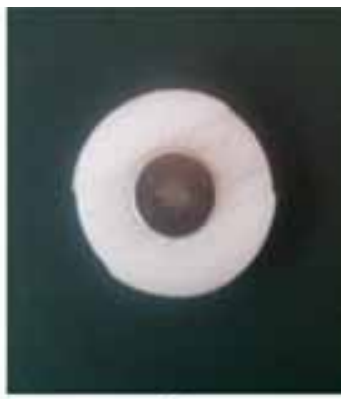

(b)

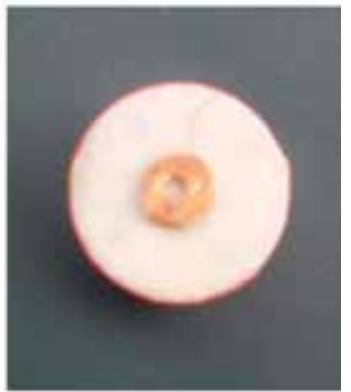

(d)

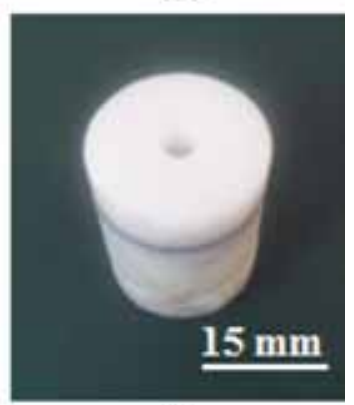

(f)
Figure 2. Pictures of the AEH in different phases of the assembly: (a) magnet holder for holding permanent magnet; (b) magnet placed in the magnet holder; (c) latex membrane bonded to the bottom of Helmholtz cavity; (d) coil attached to the latex membrane; (e) the sub-assembly of Helmholtz cavity, latex membrane and coil placed on the magnet holder; (f) neck part is placed on top of the Helmholtz cavity.

Hampshire, Illinois, USA), HR and magnet holder are produced. These parts are fabricated through conventional machining. For the circular membrane, latex rubber (Gloves, XR10002, Xinran medical Co., Ltd, China) is used, as it is highly flexible and has better resistance to punctures $[26,27]$. The stiffness of the membrane affects the power output of the harvester, as the amplitude of oscillation of the membrane is related to stiffness. For low SPL acoustic environment, usually a membrane with lower stiffness is preferred. With the less stiff harvester's membrane, relatively large amplitudes of membrane's oscillation would result even at low SPLs, which lead to greater change in the magnetic flux density over the coil and ultimately the increase in the voltage induction and power
Table 1. Main parameters and dimensions of the assembled prototype.

\begin{tabular}{lc}
\hline Description & Value \\
\hline Dimensions of harvester & $30 \mathrm{~mm}$ \\
Diameter & $24 \mathrm{~mm}$ \\
Thickness & \\
Dimensions of magnet & $12.7 \mathrm{~mm}$ \\
Diameter & $2.54 \mathrm{~mm}$ \\
Thickness & \\
Dimensions of coil & $8 \mathrm{~mm}$ \\
Diameter & $3 \mathrm{~mm}$ \\
Thickness & $50 \Omega$ \\
Resistance of coil & 1953 \\
Number of turns of coil & $0.67 \mathrm{~g}$ \\
Coil mass & $100 \mu \mathrm{m}$ \\
Membrane thickness & $13 \mathrm{~mm}$ \\
Membrane diameter & $1.32 \mathrm{~T}$ \\
Magnet (NdFeB), B & $2.41 \mathrm{~g}$ \\
Magnet mass & $1.5 \mathrm{~mm}$ \\
Gap between coil and magnet &
\end{tabular}

generation would be obtained. However, for relatively high SPL acoustic environment, a stiffer membrane would perform better. This is due to the reason that the power from the electrodynamic harvester also depends on the frequency, therefore the membrane with higher stiffness will have high resonant frequency and thus would result in producing more power [2].

To produce the wound coil, a copper wire of $40 \mu \mathrm{m}$ radius is utilized. Manual winding equipment is used to produce a wound coil of $8 \mathrm{~mm}$ diameter, $3 \mathrm{~mm}$ thickness and 1953 turns. Commercially available small size $\mathrm{NdFeB}$ magnet is placed in the magnet holder just under the membrane (coil) to provide magnetic flux to the wound coil. The dimension selection of the coil is based on the magnet size. For small size magnets usually the coil with smaller thickness and diameter is preferred. Furthermore, in such a case the gap between coil and magnet is also kept small. This is due to the fact that if the diameter of the coil is kept larger than the magnet's size or the gap between the coil and the magnet is adopted large, then a very high nonuniform magnetic flux density (normal component) is experienced by the wound coil. Due to which the outer coil turns experiences either very low magnetic flux density or a magnetic flux density with opposite polarity, which ultimately reduces the voltage and power production from the harvester [28].

With the help of superglue (Fixee Co., Lahore, Pakistan) the parts of the prototype are attached and assembled. First the magnet is placed and bonded in the magnet holder using superglue as shown in figure 2(b). The latex membrane is then bonded on the bottom side of the Helmholtz cavity as depicted in figure 2(c). Afterward the coil is attached on the bottom side of the latex membrane, figure 2(d). The HRmembrane sub-assembly is then placed and fixed on the 
magnet holder using superglue, figure 2(e). Finally the neck part of the HR is bonded to the top side of the Helmholtz cavity, figure 2(f). In table 1 the parameters and dimensions of the assembled harvester are listed.

\section{Experimental equipment and characterization of the prototype}

Figure 3 shows the experiment equipment used for the characterization of the developed prototype. The experimental equipment is composed of an Instek GOS-6112 oscilloscope, plane wave tube, Ringford CZ034A microphone, sound speaker, Instek GFG-8020H function generator and a Kenwood A7-X power amplifier. In the testing equipment, function generator is used to produce a sinusoidal signal of a specific frequency and amplitude. Using power amplifier the signal from the function generator is amplified. The amplified signal is then supplied to the speaker that generates an acoustical wave. The acoustic wave impinges on the prototype after passing through the plane wave tube. The plane wave tube ensures that a smooth sinusoidal acoustic wave, with a constant amplitude and frequency impinges on the prototype. Furthermore, instead of a plane wave tube, if the harvester is characterized in front of speaker in an open air, there is a high probability that the acoustic wave impinging the prototype is not purely sinusoidal but slightly random. Actually, this wave disturbance might have been resulted due to the sound reflection from the objects placed near the testing equipment. Moreover, the plane wave tube helps in measuring a more accurate value of SPL near the energy harvester. To measure the SPL of the generated acoustical wave on the prototype a microphone is placed near the prototype in the testing equipment. The signals from the microphone and prototype are examined using oscilloscope.

The SPL of the acoustic energy during the experimentation is calculated from the voltage measurement of the microphone with equation

$$
\begin{aligned}
S P L(d B) & =20 \log _{10}\left(\frac{P_{r m s}}{P_{r e f}}\right)=20 \log _{10}\left(\frac{V_{r m s}}{P_{r e f}} \times \frac{P_{r m s}}{V_{r m s}}\right) \\
& =20 \log _{10}\left(\frac{V_{r m s}}{P_{r e f}} \times \frac{1}{S}\right)
\end{aligned}
$$

where $P_{\text {ref }}=20 \mu \mathrm{N} / \mathrm{m}^{2}=0 \mathrm{~dB}$ is the minimum hearable sound pressure and $S=12 \mathrm{mV} / \mathrm{N} / \mathrm{m}^{2}$ is the microphone's sensitivity.

Figure 4 depicts the load voltage (rms value) produced by the energy harvester prototype as a function of operational frequency at various SPLs. An external load equivalent to the coil resistance $(50 \Omega)$ is attached to the AEH, and the prototype is subjected to frequency sweeps. The

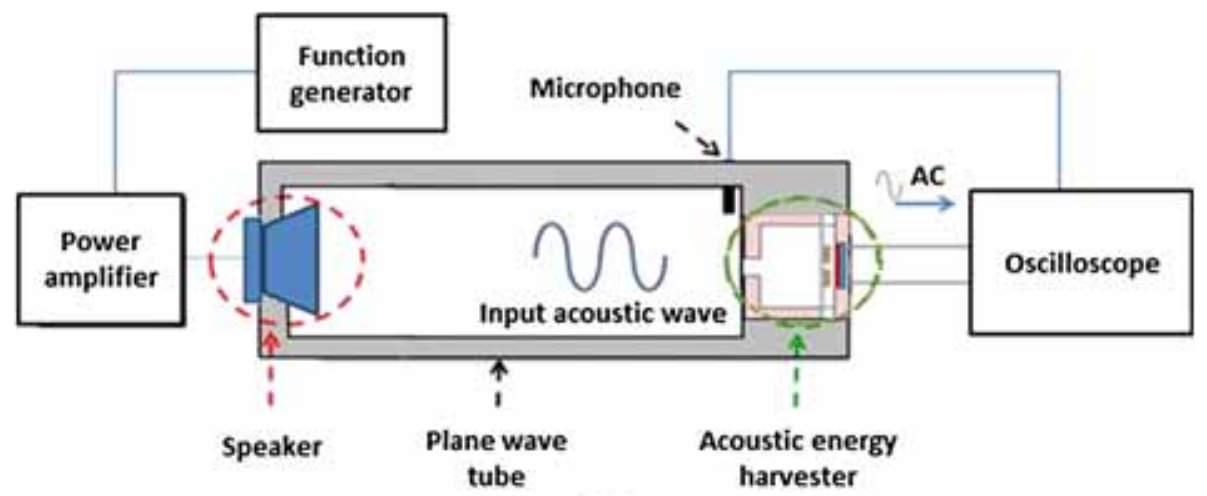

(a)

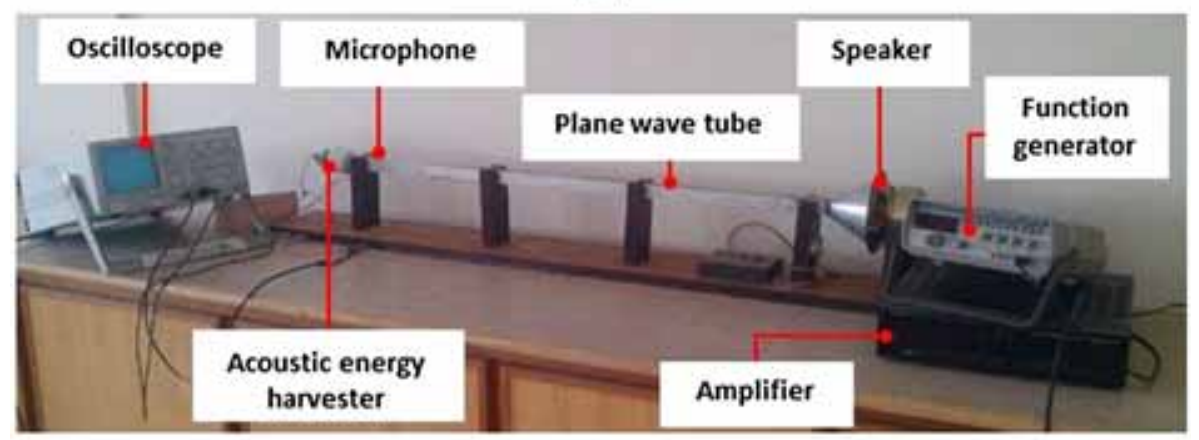

(b)

Figure 3. Experimental equipment for the harvester's characterization (a) schematic diagram; (b) developed experimental equipment. 


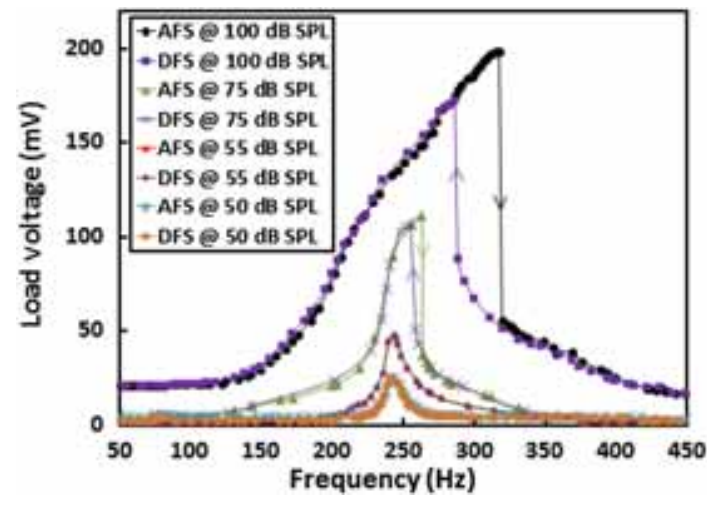

Figure 4. Load voltage vs exciting frequency under various SPLs.

harvester is exposed to both ascending frequency sweep (AFS) from 50 to $450 \mathrm{~Hz}$ and descending frequency sweep (DFS) back from 450 to $50 \mathrm{~Hz}$. From experimentation, it is clear that the response of the harvester under low SPLs is linear; however, the behavior of the harvester under high SPLs is non-linear. The reason for non-linear behavior of the harvester is the non-linear stiffness of the latex membrane. Normally the stiffness of the membrane comes from the bending stresses and stretching that is produced in the membrane. The stiffness of the membrane under low SPL is only because of bending stresses, as stretching (tensile stresses) under low SPL is very small and can be neglected. This results in linear membrane's stiffness. However, as SPL is increased, the deflection in the membrane increases and causes the stretching (tensile stresses) to also increase. These stretching, tensile stresses become significant under high SPL that ultimately increases the membrane stiffness $[29,30]$. The harvester exhibits single resonant frequency under linear response. This indicates the constant membrane stiffness. However, the response curve of the harvester is tilted towards higher frequency under high SPLs. Moreover, due to the non-linear stiffness of the membrane a jump up and a jump down phenomena are also observed during AFS and DFS in the harvester response curve. The developed prototype when subjected to a SPL of $100 \mathrm{~dB}$, under nonlinear operation, it generated a peak load voltage of $198.7 \mathrm{mV} \mathrm{rms}$ at a resonant frequency of $319 \mathrm{~Hz}$.

The harvester's resonant frequency during AFS as a function of SPL is shown in figure 5. Due to the non-linear response of the membrane a shift in the resonant frequency of the energy harvester is observed. The response of the harvester is linear below $55 \mathrm{~dB}$ SPL. The resonant frequency $(241.1 \mathrm{~Hz})$ of the harvester remains constant in the linear regime. However, above $55 \mathrm{~dB}$ SPL the behavior of the harvester is non-linear and the resonant frequency in the nonlinear regime varies from 241.1 to $319 \mathrm{~Hz}$ for a change in SPL from 55 to $100 \mathrm{~dB}$. Moreover, the nonlinear behavior of the harvester helps in increasing the frequency range for its operation. As shown in figure 5, the harvester has only a single resonant frequency $(241.1 \mathrm{~Hz})$ in the linear regime of

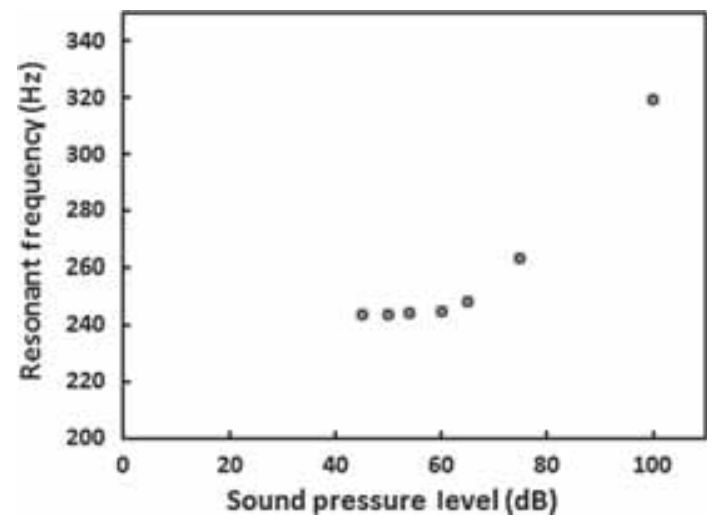

Figure 5. Harvester's resonant frequency as function of SPL.

operation; however, in the nonlinear regime, the harvester's resonant frequency varies from 241.1 to $319 \mathrm{~Hz}$ depending upon the SPL. The nonlinear behavior of the harvester can be exploited to harvest energy from random and chaotic acoustic environments, since the amplitude and frequency of such acoustical noise changes continuously. For example, if the harvester is exposed to a random acoustic energy where the amplitude of SPL ranges from 30 to $130 \mathrm{~dB}$ and the frequency bandwidth is spread from 200 to $400 \mathrm{~Hz}$ then there is high probability for the harvester to resonate and harvest this random energy in comparison to the harvester that operates in the linear regime only and has a single resonant frequency independent of the SPL [8].

In figures 6 and 7, the voltage and power curve for the harvester under different SPLs are shown respectively. Under variable load resistance, the harvester is excited at 55, 75 and $100 \mathrm{~dB}$ SPLs and 241.1, 263 and $319 \mathrm{~Hz}$ resonant frequency respectively. It is clear from figures 6 and 7 that higher the load resistance, smaller is the current passing through it and greater is the voltage across the resistor. At $50 \Omega$ (equal to coil resistance) load resistance, the harvester delivered a maximum power, thus satisfying the maximum power transfer theorem [31]. The overall impedance of the coil is due to the combine effect of its

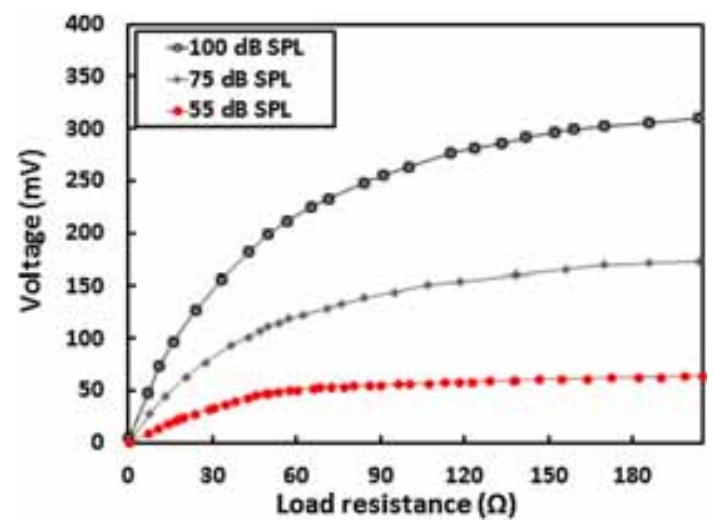

Figure 6. Load voltage produced by the harvester versus load impedance under various SPLs. 


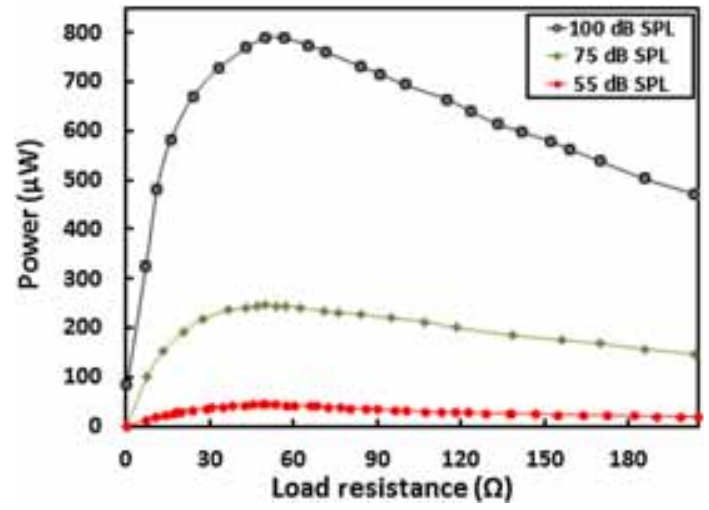

Figure 7. Power generated by the harvester versus load impedance under various SPLs.

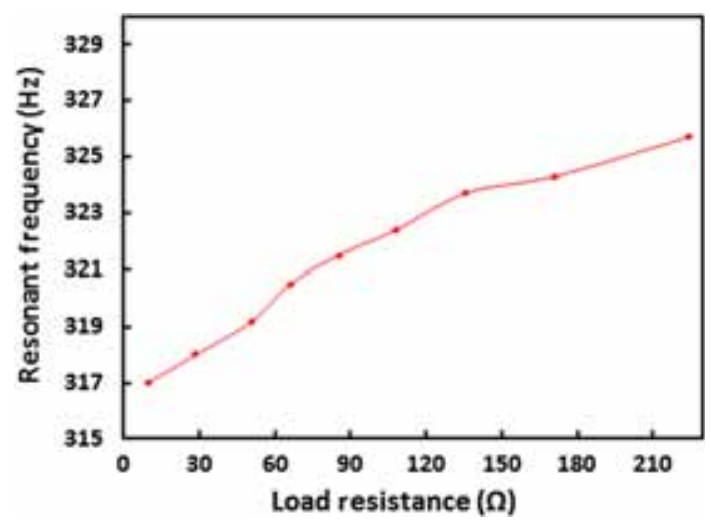

Figure 8. Resonance frequency of the AEH as a function of load impedance.

resistance and inductive reactance. However, the effect of the inductive reactance on the overall impedance of the coil is negligible. The inductance of the developed multi-layer spiral wound coil, calculated using wheeler formula, is $1.2 \mathrm{mH}[9,32,33]$. Therefore for the frequency range (from 50 to $450 \mathrm{~Hz}$ ) of the harvester, the inductive reactance of the coil ranges from 0.3 to $3.39 \Omega$ [34], that results in a very small change of the coil's overall impedance, which is from 50.00089 to $50.1 \Omega$. Therefore, the optimum load condition for the harvester has not changed much from $50 \Omega$, which is equivalent to the coil resistance. Moreover, under optimum load condition when the prototype is exposed to an SPL of $100 \mathrm{~dB}$ and a frequency of $319 \mathrm{~Hz}$ (resonant frequency), it delivered a peak power of $789.65 \mu \mathrm{W}$.

Figure 8 shows the shift in the harvester's resonant frequency due to load resistance. The measurement in figure 8 is taken at an SPL of $100 \mathrm{~dB}$. As shown, with the increase in the load resistance the resonant frequency of the harvester increases slightly. This is due to the fact that relatively high current flows through the coil of the harvester at the smaller load resistances, and attributed to slightly higher electrical damping that reduces the resonant

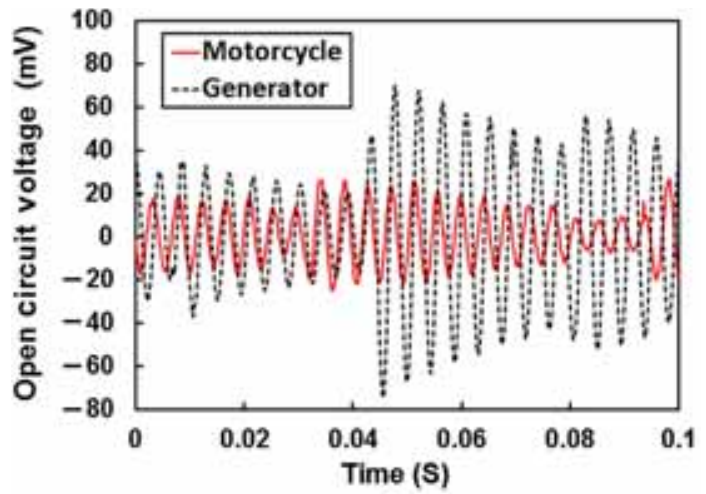

(a)

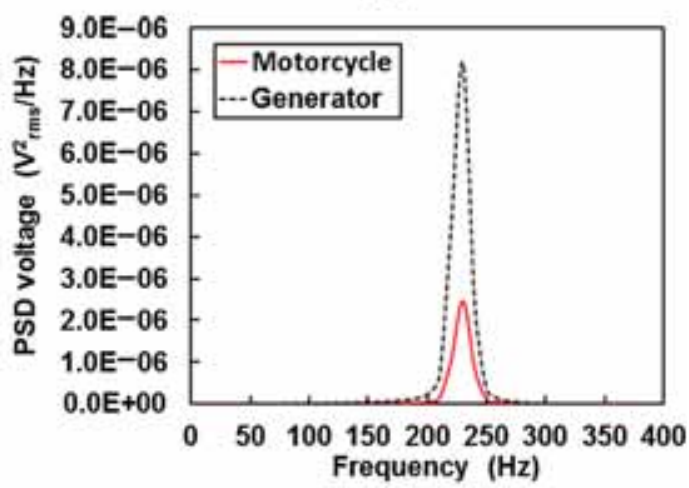

(b)

Figure 9. Response of the harvester in surrounding of motorcycle and electric generator (a) Output voltage, (b) PSD of the output voltage.

frequency of the harvester by a small amount. However, at higher load resistances, the current in the coil is relatively lower, which attributes to the reduced electrical damping and increased resonant frequency of the AEH.

The developed energy harvester is also characterized in a real environment in the surrounding of ambient acoustic energy sources such as motorcycle (CD-70, Atlas Honda Co., Pakistan) and household electrical generator $(8.8 \mathrm{kVA})$. During these measurements, National Instruments ${ }^{\mathrm{TM}}$ data acquisition (DAQ) card and NI LabVIEW software is used to acquire the signals from the harvester and the microphone simultaneously.

Figure 9(a) shows the time response (open circuit voltage) and of the harvester when it is exposed to the ambient acoustical noise produced by the motorcycle and household electric generator. During this experimentation, the harvester is placed about $25 \mathrm{~cm}$ and $35 \mathrm{~cm}$ away from the muffler of the motorcycle and electric generator respectively. Since the real acoustical noise of the motorcycle is random and chaotic therefore the output signal from the harvester, as shown in figure 9(a), is also random. In the surrounding of motorcycle where the ambient acoustical noise ranges from 30 to $90 \mathrm{~dB}$ SPL, the developed AEH generated open circuit voltage amplitude of $25 \mathrm{mV}$. 
Table 2. Comparison of the AEHs.

\begin{tabular}{|c|c|c|c|c|c|c|c|c|}
\hline Type & $\begin{array}{l}\text { SPL } \\
(\mathrm{dB})\end{array}$ & $\begin{array}{l}\text { Frequency } \\
\qquad(\mathrm{Hz})\end{array}$ & $\begin{array}{l}\text { Internal } \\
\text { resistance } \\
(\Omega)\end{array}$ & $\begin{array}{c}\text { Voltage } \\
\text { generated } \\
(\mathrm{mV})\end{array}$ & Power $(\mu \mathrm{W})$ & $\begin{array}{c}\text { Device } \\
\text { dimensions } \\
\left(\mathrm{cm}^{3}\right)\end{array}$ & $\begin{array}{l}\text { Power density } \\
\left(\mu \mathrm{W} / \mathrm{cm}^{3}\right)\end{array}$ & Ref. \\
\hline \multirow[t]{9}{*}{ Piezoelectric } & 149 & $13.57 \times 10^{3}$ & $1 \times 10^{3}$ & - & $6 \times 10^{-6}$ & 2.445 & $2.94 \times 10^{-6}$ & $\begin{array}{c}\text { Horowitz } \\
\text { et al [17] }\end{array}$ \\
\hline & 100 & $1.758 \times 10^{3}$ & $7.5 \times 10^{3}$ & - & 7.5 & 735.652 & $10.2 \times 10^{-3}$ & $\begin{array}{c}\text { Peng et al } \\
{[18]}\end{array}$ \\
\hline & 100 & $16.7 \times 10^{3}$ & 75 & - & $140 \times 10^{-6}$ & - & - & $\begin{array}{l}\text { Kimura } \\
\text { et al [19] }\end{array}$ \\
\hline & 100 & $4.92 \times 10^{3}$ & 50 & - & $82.8 \times 10^{-6}$ & - & - & $\begin{array}{c}\text { Iizumi et al } \\
{[20]}\end{array}$ \\
\hline & 110 & 146 & $1 \times 10^{6}$ & - & 2.2 & $1.5 \times 10^{3}$ & $1.5 \times 10^{-3}$ & Li et al [21] \\
\hline & 100 & 201 & $38 \times 10^{3}$ & - & $1.43 \times 10^{3}$ & $3.97 \times 10^{3}$ & 0.36 & $\begin{array}{c}\text { Yang et al } \\
\text { [22] }\end{array}$ \\
\hline & 45 & $4.2 \times 10^{3}$ & $3.9 \times 10^{3}$ & - & $40 \times 10^{-3}$ & 47.149 & $8.48 \times 10^{-4}$ & $\begin{array}{c}\text { Wu et al } \\
\text { [35] }\end{array}$ \\
\hline & 110 & $6.28 \times 10^{3}$ & 56.8 & - & $0.68 \times 10^{-6}$ & - & - & $\begin{array}{l}\text { Matsuda } \\
\text { et al [37] }\end{array}$ \\
\hline & 100 & $24 \times 10^{3}$ & 550 & - & $11 \times 10^{-6}$ & - & - & $\begin{array}{l}\text { Shinoda } \\
\text { et al [38] }\end{array}$ \\
\hline \multirow[t]{3}{*}{ Electromagnetic } & - & 470 & - & 0.24 & - & $9 \times 10^{-3}$ & - & $\begin{array}{c}\text { Lai et al } \\
{[23]}\end{array}$ \\
\hline & 120 & 144 & 66 & - & $1.5 \times 10^{3}$ & 7.86 & $1.91 \times 10^{3}$ & $\begin{array}{c}\text { Khan and } \\
\text { Izhar } \\
{[16]}\end{array}$ \\
\hline & 100 & 319 & 50 & 198.7 & 789.65 & 13.57 & 58.19 & This work \\
\hline
\end{tabular}

Furthermore, the harvester produced an optimum open circuit voltage of $60 \mathrm{mV}$ when placed in the environment of household generator where acoustical noise ranges from 50 to $112 \mathrm{~dB}$ SPL.

The power spectral density (PSD) of the open circuit voltage produced by the AEH is shown in figure 9(b). To generate the PSD plot, the RMS averaging option available in Sound and Vibration Assistant (LabVIEW) is utilized. Close to the resonant frequency of the harvester, the PSD of open circuit voltage is normally maximum. In the environment of motorcycle, the maximum PSD value of $2.47 \times 10^{-6} \mathrm{~V}^{2} / \mathrm{Hz}$ is obtained from the harvester at the central frequency of $230 \mathrm{~Hz}$. Moreover, the harvester produced a maximum PSD value of $8.4 \times 10^{-6} \mathrm{~V}^{2} / \mathrm{Hz}$, when placed in the surrounding of electric generator.

\section{Discussion}

The developed AEH is compared with the reported AEHs in table 2. The dimensions of the devised prototype is much smaller than the AEHs reported by Peng et al [18], Li et al [21], Wu et al [35] and Yang et al [22] and is quite comparable to the harvesters produced by Horowitz et al [17] and Khan and Izhar [16]. However, the dimensions of the harvester developed in this work is bigger than the harvesters fabricated by Lai et al [23], but the harvester reported by Lai et al [23] generated much lower output voltage than the harvester developed in this work.

In comparison, the power developed by the harvester produced in this work is better from all of the reported AEHs except Yang et al [22] and Khan and Izhar [16]. However, the size of the harvester developed by Yang et al [22] is on the larger side, and the SPL to which the harvester of Khan and Izhar [16] is exposed is relatively higher than the SPL to which the harvester of this work is subjected. Moreover, in our previous work [16], the coil's turns (11845) are much greater than that in the harvester reported here, which has only 1953 turns. In Khan and Izhar [16], the magnet $(377 \mathrm{mg}$ ) is attached to the oscillating membrane, which acts as an inertial mass. This has the advantage of enhancing the power output from the harvester as power production directly depends on the inertial mass, Beeby et al [36].

Moreover, in comparison, the resonant frequency and the internal impedance of the developed harvester is lower than most of the reported AEHs.

\section{Conclusion}

A centimeter-scale electromagnetic generator for harvesting acoustic energy is developed and characterized in this work. The performance of the developed acoustic energy 
harvester (AEH) is analyzed both in laboratory and in real environment. In laboratory, under different SPLs and frequencies the efficiency of the harvester is analyzed. The response of the harvester is linear under low SPLs and nonlinear under relatively high SPLs. In the non-linear regime of operation, the developed harvester produced $198.7 \mathrm{mV}$ load voltage at an SPL of $100 \mathrm{~dB}$ and $319 \mathrm{~Hz}$ resonant frequency. However, when connected to the $50 \Omega$ load resistance it produced an optimum power of $789.65 \mu \mathrm{W}$ under resonance operation. In real environment, when the harvester is exposed to the acoustical noise of a motorcycle (CD-70) in which the SPL varied from 30 to $90 \mathrm{~dB}$, the harvester produced a maximum $25 \mathrm{mV}$ voltage and a maximum $2.47 \times 10^{-6} \mathrm{~V}^{2} / \mathrm{Hz}$ power spectral density. Moreover, the harvester produced a $60 \mathrm{mV}$ output voltage and a peak PSD of $8.4 \times 10^{-6} \mathrm{~V}^{2} / \mathrm{Hz}$ under the varying SPL of 50 to $110 \mathrm{~dB}$ when placed in the environment of an $8.8 \mathrm{kVA}$ domestic electric generator. In comparison, the performance of the harvester produced in this work is better than most of the AEHs reported in published literature. The power levels generated by the developed harvester are enough to operate a typical wireless sensor node.

\section{References}

[1] Khan F and Izhar 2015 State of the art in acoustic energy harvesting. J. Micromech. Microeng. 25: 023001 doi:10. 1088/0960-1317/25/2/023001

[2] Khan F, Sassani F and Stoeber B 2010 Copper foil-type vibration-based electromagnetic energy harvester. J. Micromech. Microeng. 20: 125006

[3] Gilbert J M and Balouchi F 2008 Comparison of energy harvesting systems for wireless sensor networks. Int. J. Autom. Comput. 5: 334-347

[4] Roundy S, Wright P and Rabaey J 2004 Energy scavenging for wireless sensor networks: With special focus on vibrations. Kluwer Academic Publishers, Norwell, MA, USA

[5] Tan Y K and Panda S K 2007 A novel piezoelectric based wind energy harvester for low-power autonomous wind speed sensor. IECON 2007 - 33rd Annu. Conf. IEEE Ind. Electron. Soc.

[6] Kang T, Fang S, Kozlov M E, Haines C S, Li N, Kim Y H, Chen Y and Baughman R H 2012 Electrical power from nanotube and graphene electrochemical thermal energy harvesters. Adv. Funct. Mater. 22: 477-489. doi:10.1002/adfm. 201101639

[7] Elfrink R, Kamel T M, Goedbloed M, Matova S, Hohlfeld D, Andel Y and Schaijk R 2009 Vibration energy harvesting with aluminum nitride-based piezoelectric devices. $J$. Micromech. Microeng. 19: 094005

[8] Khan F, Sassani F and Stoeber B 2013 Nonlinear behaviour of membrane type electromagnetic energy harvester under harmonic and random vibrations. Microsyst. Technol. 19(9): $1-13$

[9] Khan F, Stoeber B and Sassani F 2014a Modeling and simulation of linear and nonlinear MEMS scale electromagnetic
452 energy harvesters for random vibration environments. Sci. World J. 2014: 74258 doi:10.1155/2014/742580

[10] Georgiadis A, Collado A, Via S and Meneses C 2011 Flexible hybrid solar/EM energy harvester for autonomous sensors. Proc. 2011 IEEE MTT-S Int. Microw. Symp. Baltimore, Maryland, USA, pp. 1-4

[11] Chang S H, Wu H W and Hung C F 2013 A sound quality study of domestic electrical appliances by jury test in indoor space. Open Acoust. J. 6: 11-19 doi:10.2174/187483760130 6010011

[12] Hu X, Aoki T and Tokura N 2012 The feature of weak shock wave propagated in a overlong tunnel. Open J. Fluid Dyn. 2: 285-289

[13] Bartlett M L and Wilson G R 2002 Characteristics of small boat signatures. J. Acoust. Soc. Am. 112: 2221.

[14] Grujić S, Mihailović A, Kiurski J, Adamović S and Adamović D 2011 Noise level investigation in printing industry in Novi Sad, Serbia. Int. J. Environ. Earth Sci. Eng. 05(4): 224-226

[15] Bedi R 2006 Evaluation of occupational environment in two textile plants in Northern India with specific reference to noise. Ind. Health 44: 112-116

[16] Khan F and Izhar 2013 Acoustic-based electrodynamic energy harvester for wireless sensor nodes application. Int. J. Mater. Sci. Eng. 1: 72-78

[17] Horowitz S B, Sheplak M, Cattafesta L N and Nishida T 2006 A MEMS AEH. J. Micromech. Microeng. 16: 174-181

[18] Peng X, Wen Y, Li P, Yang A and Bai X 2013 A wideband AEH using a three degree-of-freedom architecture. Appl. Phys. Lett. 103: 164106

[19] Kimura S, Sugou T, Tomioka S, Iizumi S, Tsujimoto K and Yasushiro N 2011 AEH fabricated using sol/gel lead zirconate titanate thin film. Jpn. J. Appl. Phys. 50: 187-190

[20] Iizumi S, Kimura S, Tomioka S, Tsujimoto K,Uchida Y, Tomii K, Matsuda T and Nishioka Y 2011 Lead zirconate titanate AEHs utilizing different polarizations on diaphragm. Proc. Eng. 25: 187-190

[21] Li B, Laviage A J, You J H and Kim Y J 2013 Harvesting low-frequency acoustic energy using quarter-wavelength straight-tube acoustic resonator. Appl. Acoust. 74: 1271-1278

[22] Yang A, Li P, Wen Y, Lu C, Peng X, He W, Zhang J and Wang D 2014 Note: High-efficiency broadband acoustic energy harvesting using Helmholtz resonator and dual piezoelectric cantilever beams. Rev. Sci. Instrum. 85: 1-3

[23] Lai T, Huang C and Tsou C 2008 Design and fabrication of acoustic wave actuated microgenerator for portable electronic devices. Symp. DTIP of MEMS \& MOEMS, Nice, France, pp. 28-33

[24] Blackstock D T and Atchley A A 2001 Fundamentals of physical acoustics. J. Acoust. Soc. Am. 109(4): 1274-1276 doi:10.1121/1.1354982

[25] Rossi M 1988 Acoustics and electro acoustics. Artech House, Norwood, MA

[26] Evangelisto M 1997 Latex allergy: The downside of standard precautions. Today's Surgical Nurse 19(5): 28-33

[27] Korniewicz D M 1997 Intelligently selecting gloves. Surg. Serv. Manag. 3(2): 13-15

[28] Khan F, Stoeber B and Sassani F 2014b Modeling of linear micro electromagnetic energy harvesters with nonuniform magnetic field for sinusoidal vibrations. Microsyst. Technol. 21(3): 683-692. doi:10.1007/s00542-014-2359-5 
[29] Khan F, Sassani F and Stoeber B 2010 Vibration-based PDMS membrane type electromagnetic power generator for low vibration environments. Canadian Society for Mechanical Engineering Forum (Victoria, Canada)

[30] Rao J S and Gupta K 1999 Introductory course on theory and practice of mechanical vibration. New Age Publishers, New Delhi

[31] Wangsness R 1986 Electromagnetic fields. 2nd edn, John Wiley \& Sons, Inc. Hoboken

[32] Ballou G (2008) Handbook for sound engineers, 4th edn, Oxford, UK

[33] Thompson M T 1999 Inductance calculation techniques part II: approximations and handbook methods power control and intelligent motion [online]. Available from http://www. thompsonrd.com/induct2.pdf. Accessed 24 July 2015

[34] Boylested R L 1996 Introductory to circuit analysis, 8th edn, Prentice Hall, New Jersey
[35] Wu L Y, Chen L W and Liu C M 2009 Acoustic energy harvesting using resonant cavity of a sonic crystal. Appl. Phys. Lett. 95: 013506. doi:10.1063/1.3176019

[36] Beeby S P, Torah R N, Tudor M J, Glynne J P, Donnell T, Saha C R and Roy S 2007 A micro electromagnetic generator for vibration energy harvesting. J. Micromech. Microeng. 17: 1257-65

[37] Matsuda T, Tomii K, Hagiwara S, Miyake S, Hasegawa Y, Sato T, Kaneko Y and Nishioka Y 2013 Helmholtz resonator for lead zirconate titanate Acoustic energy harvester. J. Phys. Conf. Ser. 476: 012003 doi:10.1088/1742-6596/476/1/ 012003

[38] Shinoda S, Tai T, Itoh H, Sugou T, Ichioka H, Kimura S and Nishioka Y 2010 Lead zirconate titanate AEH proposed for microelectromechanical system/IC integrated systems. Jpn. J. Appl. Phys. 49: 04DL21 